ingoes themselves were also secured. The nests collected differed from the conventional idea of a flamin go's nest in being much lower and of a greater diameter. Doubtless the height of the nest is governed by the rise of the water. Built wholly of mud, which is scooped up from about the base of the nest by the bird, it is necessary that the site chosen shall be near enough to water to insure an abundant supply of soft material. Such a site, however, brings the nest with in reach of the tide, and places it in a low situation, which may be subsequently flooded by heavy rains. Consequently the birds must build their nests high enough to protect their contents from the water.

These two conditions have resulted in the production of a mud cone, which, in the colonies examined, was never more than twelve inches in height, but those as high as eighteen inches have been reported. In the slightly hollowed top of the adobe dwelling house a single white egg is laid.

The single nest here figured, however, has been excavated to a greater depth than the original in order to lighten it for transportation purposes.

THE GREAT ROTORUA GEYSER OF NEW ZEALAND.

Yellowstone Park is reputed to have the most magnificent geysers in the world; but their reputation is based upon the statements of travelers who have never been to New Zealand, and who know nothing of its natural wonders.

Leaving Auckland by a fast express train, a journey of eight hours brings one to Rotorua, where may be seen the most splendid geyser which is probably to be found anywhere in the world. To give one some idea of the magnitude of the geyser, I need mention only th height of some of the surrounding objects. On the extreme left of the picture herewith reproduced, over the "Inferno Crater" (which contains a seething lake of water) is a small shelter shed, 450 feet above the plain. The surface of the water

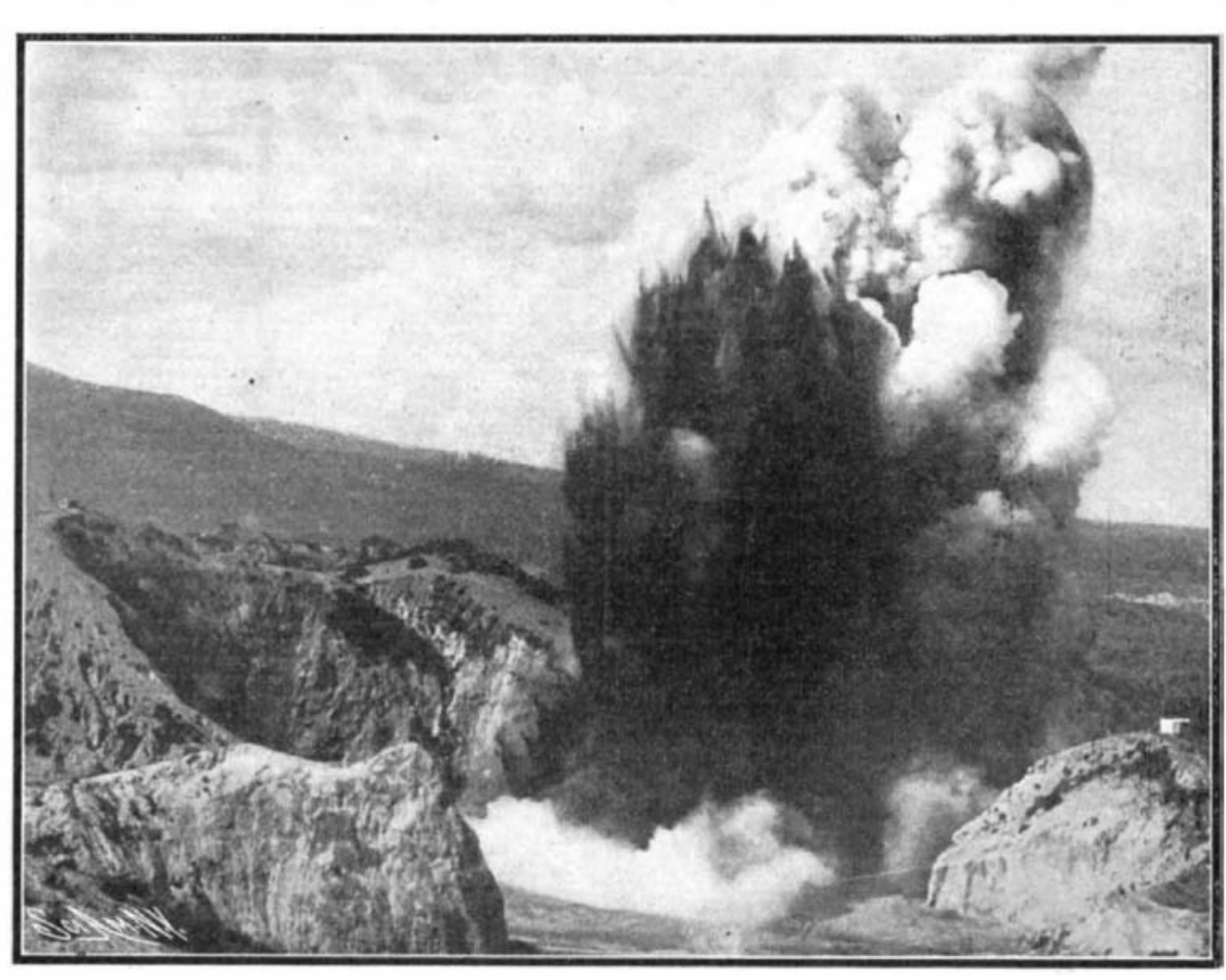

about 40 feet below this plain. From these figures it is easy to compute the height of the eruption. In the instance illustrated, that height must be about 900 feet. This is by no means exceptional. Higher "shots" have been recorded. I have myself seen a shot computed at 1,200 feet. Some months ago the area of the
basin was measured in a small boat by a Mr. Buckeridge and a guide. They found that the area is about $21 / 2$ acres, from which it may be inferred that this gey ser may well be called the largest in the world.

The geyser plays about twenty-two times each month, is very erratic, and gives no warning when it is about to erupt. The theory is advanced that the basin is somewhat like a funnel, and that when the water and stones are ejected, the larger stones return and jam in the neck, thereby choking the outlet, so that an enormous pressure of steam must shift them. When the pressure is sufficiently great to blow out the obstructions, it naturally would eject water to a great height.

The theory, however, is at best rather fanciful

This geyser is not the only one to be seen in the vicinity. Others may be mentioned, such as the Pohutu, Wairoa, Feather, Papakura, and others, besides mud volcanoes.

\section{A Saw-Proof Bar.}

Perry D. Zeigler has invented a bar which cannot he sawed or cut through, for use in connection with prison-cells, windows or doors, and safety-vaults.

In carrying out his invention he takes a metallic bar of any suitable material, preferably iron or steel, and in the bar adjacent to its corners he provides longitudinal apertures. In the case of a round bar a numker of apertures adjacent to its periphery are provided, and, if desired, as an extra precaution one or more holes may be present. The bar having been formed as described, molten glass or the like is poured into the apertures. After this has cooled, the inventor claims it would be impossible to saw through the bar, for the reason that the saw would not cut the glass, and only a partial fracture of the bar could he obtained.

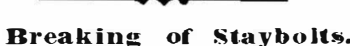

taybolts break more frequently in bad-water districts than in those districts where the water is ireer from incrustating solids, says $\mathrm{Nr}$ H. A. Fergusson, in a paper rear before the Western Railway Club of America. This is not to be at tributed to the action of the water on the bolts, but to the fact that such engines are washed out very much more frequently, with consequent vibration of the bolts each time. There is apparently no rem edy for this, where water-purifying stations are absent, except flexible staybolt, and while num bers of these have been de signed and tried, there are none of them that will not infexible through the the scale formations around bolt, therefore, is one which has the greatest flexibility, and which cannot be affected

THE GREAT ROTORUA GEYSER IN ERUPTION. by scale.

\begin{tabular}{|c|c|c|c|}
\hline 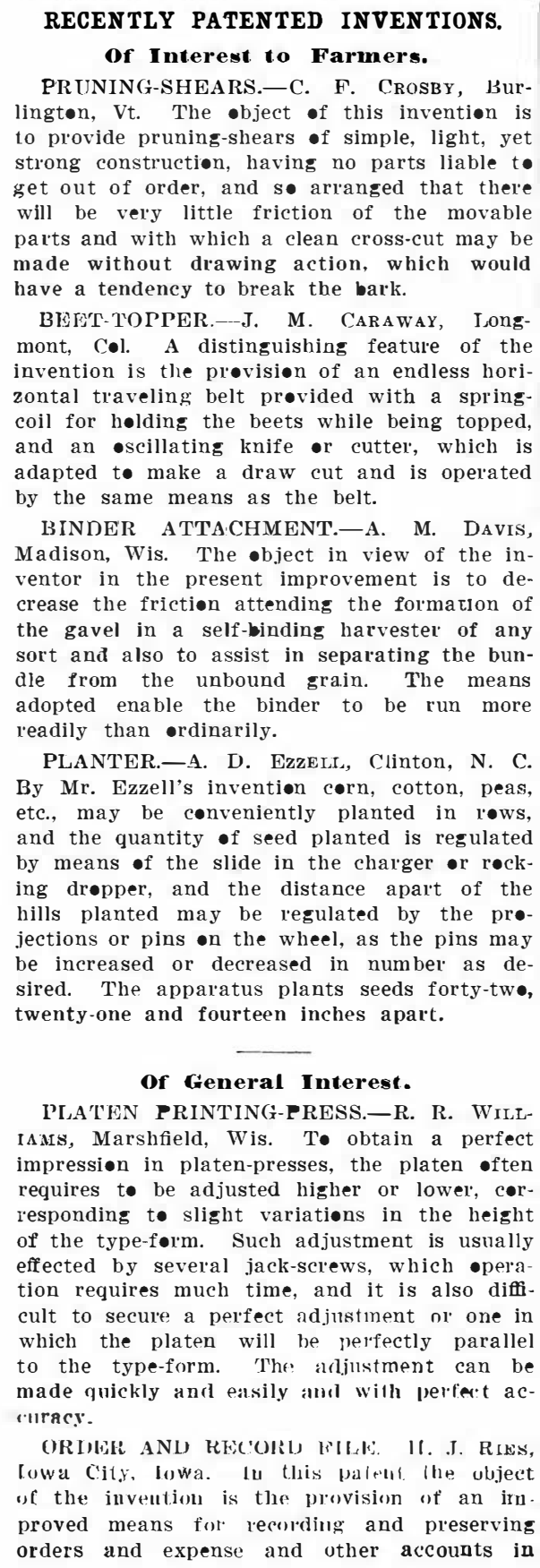 & 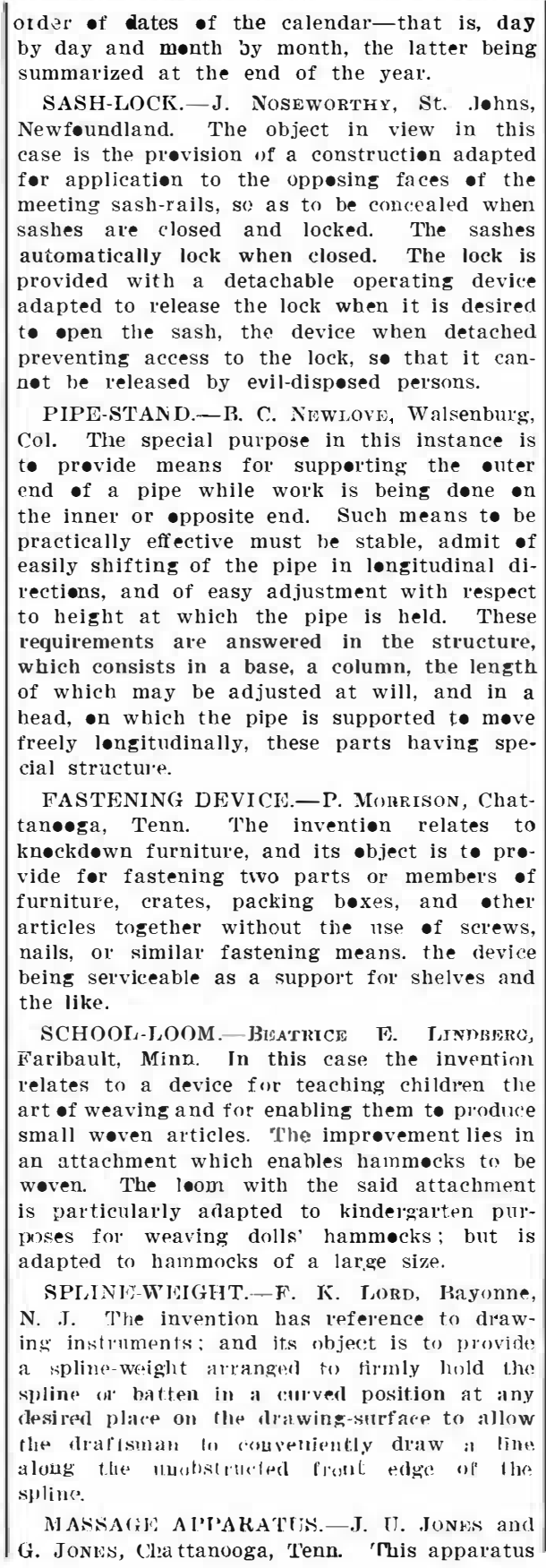 & 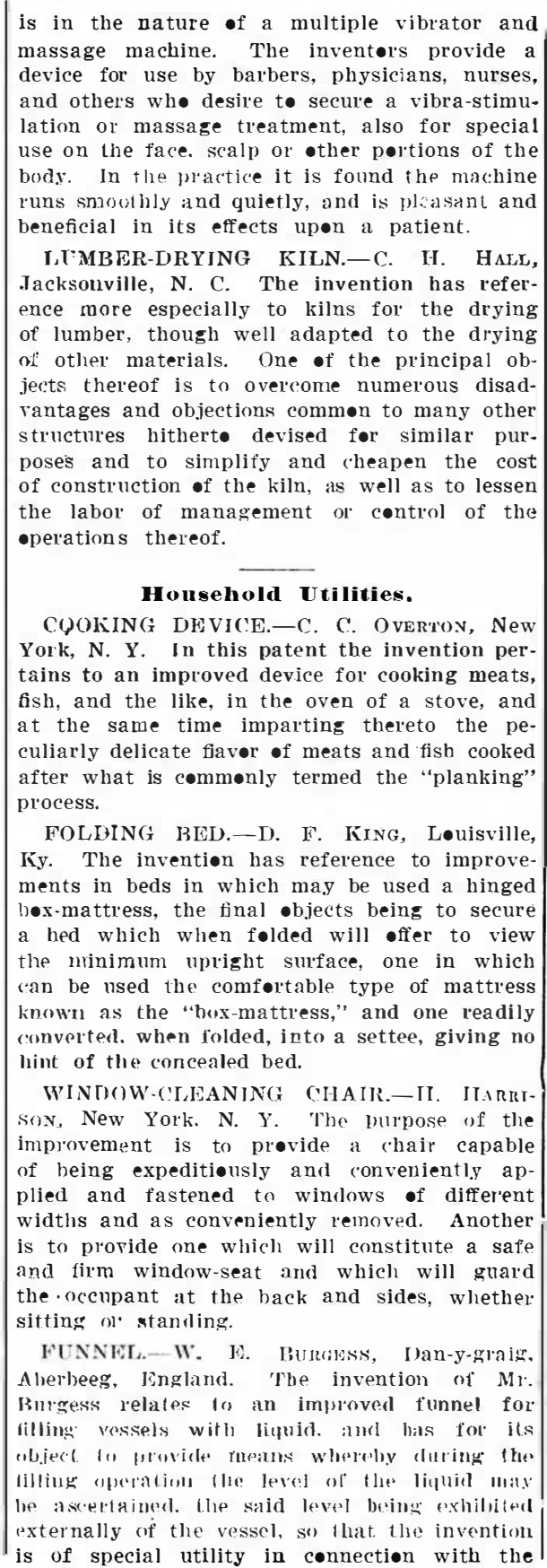 & 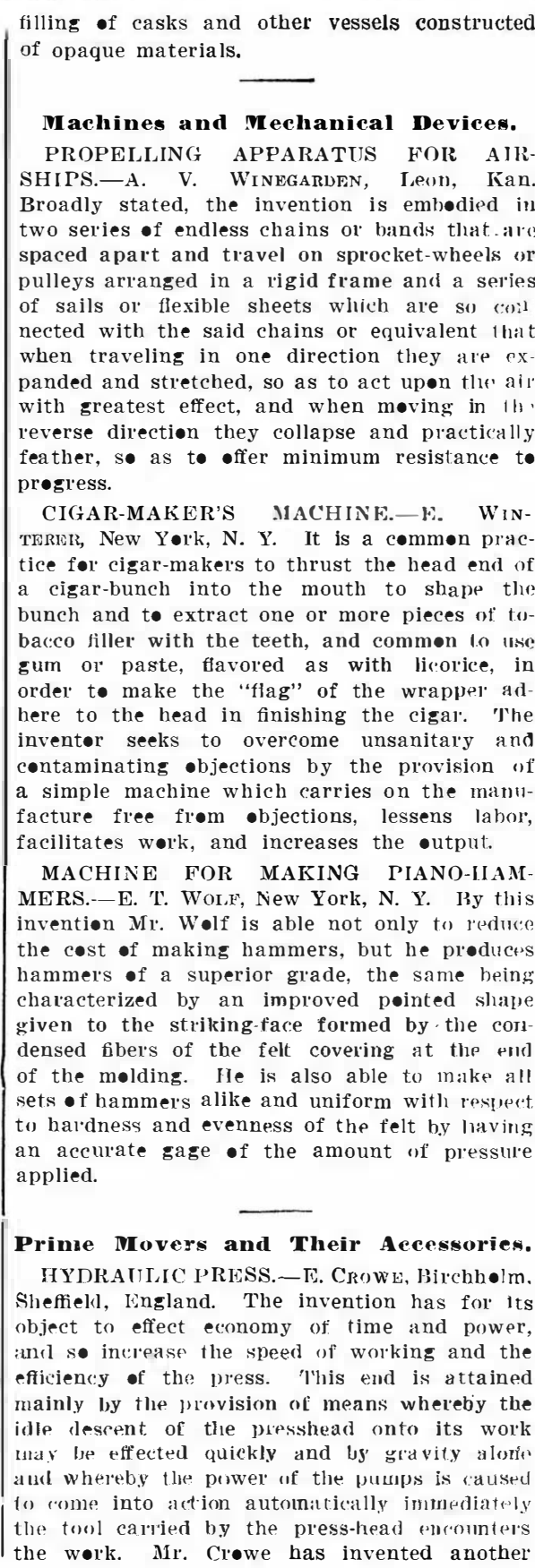 \\
\hline
\end{tabular}

